\title{
Questionnaire-based risk assessment for amoebic gill disease (AGD) and evaluation of freshwater bathing efficacy of reared Atlantic salmon Salmo salar
}

\author{
G. M. Douglas-Helders ${ }^{1, *}$, S. Saksida ${ }^{2}$, B. F. Nowak ${ }^{1}$ \\ ${ }^{1}$ School of Aquaculture of the Tasmanian Aquaculture and Fisheries Institute, Aquafin Cooperative Research Centre, \\ University of Tasmania, Locked Bag 1-370, Launceston 7250, Tasmania, Australia \\ ${ }^{2}$ Sea to Sky Veterinary Service, Steelhead Rd, Cambell River, British Columbia V9W 4P4, Canada
}

\begin{abstract}
Factors causing amoebic gill disease (AGD), the main disease affecting the salmonid industry in Tasmania, are largely unknown. Managers of 57 sites, from 4 countries, in both the Southern and Northern Hemisphere were questioned regarding the 2000 smolt year-class Atlantic salmon. Questions included site characteristics, fish population characteristics, husbandry and management programs, through to freshwater bathing characteristics. Possible risk factors for AGD outbreaks that were identified in this study using farm managers' opinions were mixed sex stocks (Tasmania), downstream positioning from other salmonid farming sites (pooled), tidal sites (Tasmania), depth of site (pooled), rate of salinity change in halocline and depth of halocline (pooled, Tasmania), phytoplankton blooms (pooled, Tasmania), antifouling paints (Tasmania, overseas) and automated feeding (pooled, overseas). The information from farm managers suggested that freshwater bathing is less effective with smaller bathing cages and lower levels of saturated oxygen in the bathing water. Risk factors could not always be determined due to the complex interactions between the biological and chemical environment, host and pathogenic factors, coupled with low sample numbers.
\end{abstract}

KEY WORDS: AGD · Risk factors · Questionnaire survey · Freshwater bathing · Treatment

\section{INTRODUCTION}

Presently, amoebic gill disease (AGD) is the main disease that affects the salmonid industry in Tasmania (Nowak 2001) and is of lesser importance in other countries (Munday et al. 2001). The pathogen Neoparamoeba pemaquidensis is endemic and free-living in the marine environment (Page 1987, Dyková et al. 2000), with a worldwide spread (Cann \& Page 1982). AGD outbreaks have been reported in Tasmania (Munday et al. 1990, 1993), Ireland (Rodger \& McArdle 1996, Palmer et al. 1997), France (Findlay \& Munday 1998), Spain (Dyková et al. 2000), New Zealand (Clark \& Nowak 1999), Washington State and California, USA (Kent et al. 1988), and in Chile (D. Groman \& P. Bustos pers. comm.). Affected fish species include: salmonids, such as Atlantic salmon Salmo salar; rainbow trout Oncorhynchus mykiss; chinook salmon Oncorhynchus tshawytscha and coho salmon Oncorhynchus kisutch; and non-salmonids such as turbot Scophthalmus maximus, European sea bass Dicentrarchus labrax and sharpsnout seabream Diplodus puntazzo, with Atlantic salmon and rainbow trout the more susceptible species among salmonids (Kent et al. 1988, Clark \& Nowak 1999, Dyková et al. 2000, Dyková \& Novoa 2001, Munday et al. 2001).

Increased production costs due to AGD outbreaks in Tasmania can be high, with $10 \%$ of the production cost spent on management of AGD. One of the main factors contributing to the costs of AGD are high treatment costs (Munday et al. 1990, Parsons et al. 2001). However, historical evidence suggests that mortalities in- 
crease when fish are left untreated (Munday et al. 1990). Freshwater bathing has been shown to be an effective treatment method, and is presently the main and most successful treatment method for AGD (Munday et al. 1990, Nowak 2001, Parsons et al. 2001). In a freshwater bath treatment, fish are immersed into oxygenated fresh water for up to $4 \mathrm{~h}$ (Munday et al. 1990, Parsons et al. 2001). In the field, AGD prevalence is reduced for up to $21 \mathrm{~d}$ post freshwater bath (Clark \& Nowak 1999), but a total removal of the parasite is not achieved (Parsons et al. 2001). With the high losses involved, alternative control methods should be sought in order to reduce the impact of AGD on the salmonid industry.

Those elements that increase the risk of a disease are called risk factors (Thrusfield 1995). Risk factors can be attributed to pathogen risk factors, host risk factors and environmental risk factors (Davidson 1999), and interaction of these factors can result in diseases such as AGD. These interactions can be complex (Thrusfield 1995, Frankena \& Thrusfield 1997, Menzies et al. 1998), making determination of causal factors difficult. Confounding is a common phenomenon, and many host variables such as sex and age can mask a real association between a causal factor and disease (Martin et al. 1987). Identification of true risk factors is needed before preventative measures can be developed and the disease managed effectively (Thrusfield 1995). This requires knowledge of host population characteristics and environmental conditions that promote outbreaks (Nowak 2001). This paper describes the outcomes of a questionnaire survey, which attempted to identify risk factors by gaining knowledge about the farm manager's perceptions of (1) host population characteristics, (2) general husbandry practices, and (3) environmental conditions when outbreaks occurred.

\section{MATERIALS AND METHODS}

A questionnaire was designed in 'EPED' of the software program Epi-Info (version 6.04b-c, USD Inc., Dean et al. 1995). Site managers of 57 farm sites were asked to fill in an extensive questionnaire about the 2000 smolt year-class Atlantic salmon, introduced on marine farms in 2000 and harvested in 2001. The questionnaire consisted of 94 questions that ranged in topics from historical background information, host and site characteristics, husbandry methods, and freshwater bathing efficacy as a treatment method. The questionnaire contained a mixture of (1) open (36/94), (2) closed (26/94) and (3) multiple choice (32/94) questions. The questionnaires for the Tasmanian sites were either sent via electronic mail or given to the site man- ager in person. In total, there were 31 Tasmanian marine salmon farming sites, with AGD-affected and AGD-unaffected areas geographically separated. In 14 $(45.2 \%)$ of the Tasmanian cases, the site managers were personally guided through the questionnaire, after which the site manager individually completed the questionnaires. The 17 others $(54.8 \%)$ preferred to fill out the questionnaires without an interview. Regular contact was maintained with the Tasmanian site managers once they received the questionnaire to offer discussion opportunities regarding any issues concerning the questions. A small group of salmon farmers on sites in Canada (17 sites, all without AGD history), America (3 sites, all with AGD history), Ireland (6 sites, all with suspected and confirmed AGD history), and New Zealand (1 site, with a confirmed history of AGD) were asked to participate in the questionnaire survey. Managers from selected Canadian, US, and Irish salmon farms were personally interviewed on a one-to-one basis, while the manager in New Zealand did not wish to participate.

Data from the completed questionnaires were entered and analysed using the software program Epiinfo (version 6.04b-c). Sites were classified by AGD status (positive/negative) and location (Tasmania/overseas/pooled Tasmanian and overseas). This made it possible to compare AGD occurrence with environmental and/or husbandry factors within and between (after adjustment of the dates) the 2 hemispheres. The calendar year was split into a warm season (WS), or AGD-active part, and a cool season (CS), or AGD-inactive part of the year. The WS ran from November to April (Tasmania) and from May to October (overseas), while the CS ran from May to October (Tasmania) and from November to April (overseas). The majority of AGD outbreaks in Tasmania were characterised by a greatly increased presence of white mucoid patches on affected gills between 2 consecutive gill checking procedures (gross gill assessment). A large part of the results are descriptive, in which farm and husbandry factors are described in relation to AGD. An attempt was made to identify factors that increased the likelihood of AGD occurrence on sites, based on questionnaire results.

Data were tested for homogeneity of variance using Bartlett's test. Analysis of variance (ANOVA) was used for continuous and/or ordinal data only, which were normally distributed and had equal variances. The non-parametric Kruskal-Wallis (K-W) test for continuous data was performed if assumptions of ANOVA were violated. A Mantel-Haenszel (M-H) chi-square test was used for categorical data, and if possible, risk ratios and exact $95 \%$ confidence limits were presented. If an expected categorical value was less than 5, a Fisher's exact test was used. Stratified analysis was 
performed on some of the factors to assess confounding and if the crude Odds Ratio (OR) and Mantel-Haenszel Odds Ratio were significantly different (as determined by a chi-square analysis), confounding was considered to be present. Data for Tasmanian (TAS) and overseas (OS) sites were analysed for significant differences between the 2 hemispheres. If no significant difference was found, data were pooled for analysis (Pooled); otherwise, data were analysed for each region separately. In some cases, no significant difference between the 2 regions was found, but results of TAS, OS and Pooled were presented to allow an insight into the results for each region separately as well as for the combined data. Findings in all statistical analyses were considered significant when $\mathrm{p} \leq 0.05$.

\section{RESULTS}

A total of 31 Tasmanian (91.2\% response rate) and 26 overseas $(92.9 \%$ response rate) site managers responded to the questionnaire, resulting in a total of 57 sites available for analysis. The site manager from New Zealand did not wish to participate because AGD was a minor problem in that country. Of the 31 Tasmanian sites, $25(80.6 \%)$ were AGD-positive and 6 $(19.4 \%)$ were AGD-negative in the year 2000. For the Northern Hemisphere, 9 sites (39.1\%) were AGD-positive and 17 (60.9\%) were AGD-negative. Only 3 of the overseas sites, where AGD was detected, were using the freshwater bathing treatment on an experimental basis. It was, therefore, decided to use only freshwater bathing frequencies and mortality data from Tasmanian sites to assess freshwater bathing efficacy.

\section{AGD general}

The severity of AGD outbreaks was determined using various assessment techniques, with gross gill assessment (25/66) and increased mortalities/decreased food intake (15/66) the main ones in Tasmania. Overseas outbreak severity was based on increased mortalities (6/9) and gross gill assessment (3/9). Managers reported that AGD in Atlantic salmon was first recorded on Tasmanian sites in 1988, while overseas this was in 1996. It was thought that a change in the weather patterns in Tasmania, with mainly warmer and drier conditions, resulted in a higher percentage of AGD-positive sites. At 19 (76\%) Tasmanian sites, outbreaks occurred between September and May, while at 6 (24\%) sites, outbreaks occurred in all months. On overseas sites, all AGD outbreaks were experienced from spring to autumn (April-November). In the
Tasmanian managers' opinions, the main risk factors associated with AGD were temperature (12/25, increased temperature results in increased risk), salinity (4/25, increased salinity results in increased risk), presence of other infected fish (4/25) and stocking density (3/25, increased stocking density results in increased risk). Overseas, they were biofouling (3/9) and other factors (6/9) such as fish size (2/6) and season (4/6).

The reported mortality rate due to all causes was not significantly different on AGD affected and unaffected sites in the warm season ( $p=0.388$ TAS, $p=0.108$ OS) or in the cool season ( $p=0.498$, Pooled, see Table 1$)$. The main cause of mortalities in the WS was considered to be AGD (14/29 of the Tasmanian respondents) and non-performing smolts (18/41 overseas). In the CS, the main cause of mortalities was considered to be predation, mostly due to seals both on Tasmanian and the overseas sites. Fish reported to be mostly affected by AGD on Tasmanian sites were mature salmon (12/33 respondents), adults in general (11/33 respondents) and triploids (10/33 respondents). Overseas, smolt (7/9 respondents) and adults in general (2/9 respondents) were mentioned as the fish mostly affected by AGD.

The reported average temperature at the onset of AGD outbreaks on Tasmanian sites was $15.3^{\circ} \mathrm{C}$ and for overseas sites $13.7^{\circ} \mathrm{C}$, ranging from 12 to $17^{\circ} \mathrm{C}$ in Tasmania and 9 to $17^{\circ} \mathrm{C}$ overseas. Though the average temperature on Tasmanian sites was higher, the difference in onset temperature between sites from the 2 hemispheres was not significant $(p=0.278)$. The outbreak temperature was considered to be within $1.5^{\circ} \mathrm{C}$ of the normal average of that time of the year by $68 \%$ of the site managers (17 Tasmanian sites; 6 overseas sites). In Tasmania, significantly higher mortalities were reported, both in the WS and CS, when onset temperatures of AGD outbreaks were thought to be at least $1.5^{\circ} \mathrm{C}$ above the normal average $(\mathrm{p}<0.01$ for WS and CS). For overseas sites, the sample size was too small to perform statistical analysis. Reported salinity at the onset of AGD outbreaks ranged from 32 to $35 \mathrm{ppt}$ on Tasmanian sites, and 30 to 35 ppt on overseas sites, with averages of $34.5 \mathrm{ppt}$ (SD 0.71 ) and $31.7 \mathrm{ppt}$ (SD $2.00)$, respectively. The average onset salinity was con-

Table 1. Reported total mortality averages in \% (SD) for amoebic gill disease (AGD)-positive and AGD-negative sites in the warm and cool season for Tasmanian, overseas and pooled data. na = not applicable since the 2 regions significantly differed

\begin{tabular}{|lllcc|}
\hline Season & AGD status of site & Tasmania & Overseas & Pooled \\
\hline Warm & AGD-positive & $3.72(1.93)$ & $9.80(0.00)$ & na \\
Warm & AGD-negative & $3.68(1.78)$ & $8.25(2.93)$ & na \\
Cool & AGD-positive & $0.95(1.21)$ & $0.53(0.40)$ & $0.83(1.06)$ \\
Cool & AGD-negative & $0.52(0.72)$ & $1.21(1.42)$ & $1.06(1.31)$ \\
\hline
\end{tabular}


sidered to be within 2 ppt of the normal average of that time of the year by all sites managers. Salinities at AGD outbreaks did not have any effect on the reported mortality rate in the WS and CS (TAS: $p=0.248$ in the WS, $p=0.398$ in the CS; OS: $p=0.306$ in the WS, $p=$ 0.216 in the CS).

\section{Site characteristics and AGD}

Tasmanian AGD-positive sites and all overseas sites were tidal and this was significantly associated with AGD occurrence on a site ( $p=0.004$, see Table 2). Estuarine sites were significantly shallower compared to oceanic sites, which affected the type of sea bed at these sites. The sea bed on AGD-positive pooled sites contained mud or sand in $97.1 \%$ of the cases, while on AGD-negative sites this was $60.9 \%$. The average depth at AGD-positive sites was $21.7 \mathrm{~m}$ (SD 4.8, TAS) and $16.7 \mathrm{~m}$ (SD 6.1, OS), and were in general shallower compared to AGD-negative sites, which were on average $25.8 \mathrm{~m}$ (TAS, SD 3.6) and $58.8 \mathrm{~m}$ (OS, SD 21.9). Overseas, depths of AGD-affected sites were significantly shallower than AGD-unaffected sites ( $p<0.01$, Table 2), but not on Tasmanian sites ( $p=0.059$, TAS, Table 2). The type of sea bed was significantly associated with the reported AGD status of a site using pooled data $(p<0.01)$. However, on Tasmanian sites only, this association was not seen $(p=0.803)$, possibly due to confounding with other environmental factors.

Salinity is a well-recognised risk factor for AGD (Clark \& Nowak 1999). Often salinity changes in the surface layer of the seawater column (halocline), due to freshwater run-off from rivers and/or precipitation. The reported rate of salinity change in the halocline was significantly smaller on AGD-positive sites compared to AGD-negative sites ( $p<0.01$, Pooled, see Table 2) and in Tasmania, the reported depth of the halocline was shallower $(p=0.001$ TAS, $p=0.496$ OS, see Table 2). The average reported depth of the halocline on Tasmanian sites was $0.53 \mathrm{~m}$ (SD 1.2) for AGD- positive sites and $4.00 \mathrm{~m}$ (SD 2.2) for AGD-negative sites. Overseas, these were $3.00 \mathrm{~m}$ (SD 2.5) for AGDpositive sites and $3.88 \mathrm{~m}$ (SD 0.9) for AGD-negative sites.

Phytoplankton blooms and the presence of jellyfish have been mentioned by site managers as potential risk factors. Phytoplankton blooms in Tasmania were reported to occur from late winter to mid autumn and overseas from late winter to early autumn, with maximum bloom frequencies in Tasmania in December, and overseas in September. In Tasmania, phytoplankton blooms were reported exclusively on AGD-positive sites, while overseas $36.0 \%$ of the AGD-positive sites reported blooms. In Tasmania, a significant association between the occurrence of reported phytoplankton blooms and presence of AGD was found ( $p<0.01$, see Table 2). Analysis showed that the presence of reported phytoplankton blooms on Tasmanian sites was not associated with the reported average salinity or temperature at the onset of an AGD outbreak. On overseas sites, no significant association between reported phytoplankton blooms and AGD was found, but blooms reported overseas were associated with both reported temperature $(p=0.018)$ and salinity $(p=0.030)$ at the onset of AGD. The presence of jellyfish did not seem to have an effect on the occurrence of $\operatorname{AGD}(\mathrm{p}=0.172$ TAS, $\mathrm{p}=0.660$ OS $)$.

\section{Husbandry and AGD}

Managers reported a significantly higher freshwater bathing frequency in the WS in Tasmania when the distance between cages was less than $30 \mathrm{~m}$ or when different sites were less than $2 \mathrm{~km}$ apart $(\mathrm{p}=0.011$ for sites, $\mathrm{p}<0.01$ for cages). However, AGD occurrence of Tasmanian sites was not associated with distance between sites and distance between cages. The main cage type used on Tasmanian sites was very different from those used overseas and, therefore, data could not be pooled. Tasmanian sites mainly used circular

Table 2. Risk factors for AGD derived from questionnaire results. na: could not be calculated due to insufficient data

\begin{tabular}{|lccc|}
\hline Risk factors and their direction of increased risk & Tasmania & Overseas & Pooled \\
\hline Mixed stocks $>$ female only stocks & $\mathrm{p}=0.004$ & $\mathrm{na}$ & $\mathrm{p}=0.061$ \\
One or more farming sites upstream > no farming sites upstream & $\mathrm{p}=0.104$ & $\mathrm{p}=0.059$ & $\mathrm{p}=0.016$ \\
Tidal $>$ non-tidal sites & $\mathrm{p}=0.004$ & $\mathrm{n}=0.061$ & $\mathrm{p}<0.01$ \\
Shallow $>$ deeper sites & $\mathrm{p}=0.059$ & $\mathrm{p}<0.01$ & $\mathrm{p}<0.01$ \\
Low $>$ high rate of salinity change in halocline & $\mathrm{p}=0.004$ & $\mathrm{na}$ & $\mathrm{p}=0.138$ \\
Shallow depth $>$ deeper depth halocline & $\mathrm{p}=0.001$ & $\mathrm{p}=0.496$ & $\mathrm{p}=0.023$ \\
Presence $>$ absence of phytoplankton blooms & $\mathrm{p}<0.01$ & $\mathrm{na}=0.015$ \\
Use of copper-based anti-fouling paints $>$ no use of these paints & $\mathrm{p}=0.021$ & $\mathrm{p}=0.032$ & $\mathrm{p}=0.01$ \\
Automated feeding $>$ hand feeding & $\mathrm{p}=0.145$ & $\mathrm{p}<0.01$ & $\mathrm{p}<0.01$ \\
\hline
\end{tabular}


cages $(87.1 \%)$, while overseas sites mainly used rectangular or square steel cages $(76.9 \%)$, on both AGDpositive and AGD-negative sites. The type of cage used, distance between cages, size of cages, and the depth of their nets were confounded, both on Tasmanian and overseas sites.

When using pooled data, it was shown that sites that reported AGD outbreaks with higher frequencies had 1 or more salmon farming sites upstream $(\mathrm{p}=0.016$, Pooled, see Table 2). In addition, the frequency of AGD occurrence increased with increasing numbers of farms upstream. However, this could have been confounded with the salinity gradient when travelling downstream in an estuary.

Fish are commonly protected from predators such as seals by using predator nets, which surround the sea cage nets. The use of predator nets was more common in Tasmania $(60.7 \%$ of the sites) than overseas $(26.9 \%$ of the sites). In general, the occurrence of predator nets was significantly higher on reported AGD-positive sites, compared to AGD-negative sites ( $p=0.001$, Pooled), though this relationship is likely to be confounded by geographical location. Antifouling paints, which are used to prevent biological growth on fish nets, were reported to be more commonly used on overseas sites $(100 \%)$ compared to Tasmanian sites $(45.2 \%)$. In Tasmania, antifouling paints were reported to be used significantly more on reported AGD-positive sites compared to AGD-negative sites ( $p=0.021$, see Table 2$)$. However, when data were pooled, no effect on the usage of antifouling paints on the AGD status of a site was detected ( $p=$ 0.615).

A common practice on Tasmanian salmonid farms is to employ a fallowing program, where sites are kept devoid of fish for a set period of time. There was no evidence that fallowing affected the reported AGD status on a site, possibly due to the wide range of fallowing schedules that were used and the different opinions of farm managers to how fallowing is defined. When farms were classified as those that used fallowing in some form and those that did not at all, fallowing occurred significantly more on Tasmanian reported AGDpositive sites $(\mathrm{p}=0.038)$ and reported AGD-negative overseas sites $(p=0.008)$. Fallowing was not likely to influence the AGD status on Tasmanian sites (risk ratio $[R R]=$ $2.21,0.75<\mathrm{RR}<6.53$ ), but was likely to prevent the presence of AGD on overseas sites $(\mathrm{RR}=0.23,0.11<\mathrm{RR}<$ $0.49)$. This may reflect definition differences between Tasmanian and overseas managers.
The reported minimum and maximum stocking densities of fish were in general higher on overseas sites, both on AGD-positive and AGD-negative sites, compared to Tasmanian sites (Table 3), but the differences were not significant. The average reported maximum stocking density on Tasmanian AGD-positive sites was significantly lower compared to Tasmanian AGD-negative sites ( $p=0.004$, Table 3 ). The average reported minimum stocking density was similar on AGD-positive and negative sites in Tasmania. Overseas, no difference was detected between the reported minimum and maximum stocking densities on AGD-positive and AGD-negative sites (Table 3).

Multiple species reared on a site were reported for $48.4 \%$ of the Tasmanian sites and $3.8 \%$ of the overseas sites, but was not found to significantly affect the reported AGD status of a site (Table 4). Rainbow trout (TAS) and chinook salmon (OS) were reported as cocultured species next to Atlantic salmon. The stocking of a site with diploids only or with a mix of diploids and triploids was also not associated with the reported AGD status of a site (Table 4). All AGD Tasmanian positive sites were stocked with a mix of female and male fish, or with both mixed female and male fish, and female only fish (mixed stock) rather than only female stocks. Mixed sex stocks were found to be significantly associated with the reported AGD status of a site $(\mathrm{p}=0.004$, see Table 2). Overseas, mixed sex stocks were used on all interviewed sites. Pooled data showed that $63.0 \%$ of the mixed sex stocks resided on AGD-positive sites, but was not significantly associated with the reported AGD status of a site ( $p=0.061$, see Table 2$)$.

Fish were reported to be fed either automatically, by hand, or by using a combination of the 2 methods. On Tasmanian reported AGD-positive sites, $36.0 \%$ of the fish were mechanically fed, and no association between automated feeding and reported AGD status of a site was detected ( $p=0.145$, see Table 2$)$. Overseas and pooled data showed a significant association between automated feeding and reported AGD occurrence of sites $(\mathrm{OS}, \mathrm{p}<0.01$; Pooled, $\mathrm{p}<0.01$, see

Table 3. Means of reported minimum and maximum stocking densities (SD) on reported AGD-positive and AGD-negative sites for each region. No significant difference between data from Tasmanian and overseas sites was detected

\begin{tabular}{|llcc|}
\hline Region & \multicolumn{1}{c}{ AGD status } & $\begin{array}{c}\text { Minimum stocking } \\
\text { density }\left(\mathrm{kg} \mathrm{m}^{-3}\right)\end{array}$ & $\begin{array}{c}\text { Maximum stocking } \\
\text { density }\left(\mathrm{kg} \mathrm{m}^{-3}\right)\end{array}$ \\
\hline Tasmania & AGD-positive $(\mathrm{n}=24)$ & $4.75(2.49)$ & $11.44(2.45)$ \\
& AGD-negative $(\mathrm{n}=3)$ & $2.67(2.08)$ & $16.33(3.51)$ \\
Overseas & AGD-positive $(\mathrm{n}=9)$ & $4.67(5.5)$ & $24.11(12.18)$ \\
& AGD-negative $(\mathrm{n}=17)$ & $4.41(4.93)$ & $20.41(5.69)$ \\
Pooled & AGD-positive $(\mathrm{n}=33)$ & $4.73(3.47)$ & $14.89(8.62)$ \\
& AGD-negative $(\mathrm{n}=20)$ & $4.15(4.61)$ & $19.80(5.55)$ \\
\hline
\end{tabular}


Table 4. Tabulation of husbandry options that did not significantly affect AGD outbreaks (with p-values) on Tasmanian sites for the warm (WS) and cool seasons (CS) and for reported AGD-positive (AGD+) and AGD-negative (AGD-) sites. If Tasmanian and overseas data were significantly different, no pooled data were presented (na)

\begin{tabular}{|c|c|c|c|c|c|c|}
\hline \multirow[t]{2}{*}{ Husbandry option } & \multicolumn{2}{|c|}{ Tasmania } & \multicolumn{2}{|c|}{ Overseas } & \multicolumn{2}{|c|}{ Pooled } \\
\hline & AGD+ & AGD- & AGD+ & AGD- & AGD+ & AGD- \\
\hline $\begin{array}{l}\text { Minimal distance between sites }(\mathrm{km}) \\
\text { p-value }\end{array}$ & \multicolumn{2}{|c|}{$\mathrm{p}=0.899$} & \multicolumn{2}{|c|}{$\mathrm{p}=0.801$} & \multicolumn{2}{|c|}{$\mathrm{p}=0.449$} \\
\hline $\begin{array}{l}\text { Average number of cages on site } \\
\text { p-value }\end{array}$ & $\mathrm{p}=0.990$ & $\begin{array}{l}14.8(7.3) \\
0.990\end{array}$ & $\begin{array}{r}14.0(4.0) \\
\mathrm{p}=\end{array}$ & $\begin{array}{l}11.5(9.2) \\
0.097\end{array}$ & $\begin{array}{r}14.6(6.2) \\
\mathrm{p}=\end{array}$ & $\begin{array}{l}12.4(8.7) \\
0.254\end{array}$ \\
\hline $\begin{array}{l}\text { Average maximum mesh size of nets }(\mathrm{mm}) \\
\text { p-value }\end{array}$ & $\begin{array}{r}27.2(7.9) \\
p=\end{array}$ & $\begin{array}{l}29.0(5.7) \\
0.754\end{array}$ & $\begin{array}{r}36.1(19.3 \\
p=\end{array}$ & $\begin{array}{l}44.1(9.2) \\
0.252\end{array}$ & na & na \\
\hline $\begin{array}{l}\text { Average net change frequency }\left(\mathrm{mo}^{-1}\right) \text { (WS) } \\
\text { p-value }\end{array}$ & $\begin{array}{r}1.6(0.4) \\
p=\end{array}$ & $\begin{array}{ll}1.5(0.2) \\
0.213\end{array}$ & $\begin{array}{r}0.5(0.4) \\
\mathrm{p}=\end{array}$ & $0.6(0.3)$ & & na \\
\hline $\begin{array}{l}\text { Average net change frequency }\left(\mathrm{mo}^{-1}\right)(\mathrm{CS}) \\
\text { p-value }\end{array}$ & \multicolumn{2}{|c|}{$p=0.080$} & \multicolumn{2}{|c|}{$p=0.072$} & \multicolumn{2}{|c|}{$\mathrm{p}=0.532$} \\
\hline $\begin{array}{l}\text { Multiple fish species on site }(\%) \\
\text { p-value }\end{array}$ & \multicolumn{2}{|c|}{ Sample size too small } & \multicolumn{2}{|c|}{ Sample size too small } & \multicolumn{2}{|c|}{$\mathrm{p}=0.746$} \\
\hline $\begin{array}{l}\text { Mixture of diploid and triploid stocks on site } \\
\text { p-value }(\%)\end{array}$ & $\begin{array}{r}52.0 \% \\
\mathrm{p}=\end{array}$ & $\begin{array}{l}83.3 \% \\
0.359\end{array}$ & $0 \%$ & $\begin{array}{l}0 \% \\
1.000\end{array}$ & $\begin{array}{r}38.2 \% \\
p=\end{array}$ & $\begin{array}{ll}21.7 \% \\
0.193\end{array}$ \\
\hline
\end{tabular}

Table 2). On reported AGD-positive sites, 66.7\% (OS) and $55.9 \%$ (Pooled) of the fish were fed automatically compared to reported AGD-negative sites. There was no association between the use of food additives and the reported AGD status of a site (Table 4). Non-significant associations for Tasmanian sites of AGD and site characteristics are shown in Table 4.

\section{Freshwater bathing as a treatment}

The need for freshwater bathing on Tasmanian sites was assessed either by gross gill examination (24 respondents or $58.5 \%$ ), according to a set schedule (15 respondents or $36.6 \%$ ), or when either food consumption decreased or mortalities increased (1 respondent or $2.4 \%$ each). Generally, only some of the cages on a site are affected by AGD at a particular time, and $72 \%$ of the site managers (17 sites) would bath only these AGD-affected cages, while $28 \%$ ( 7 sites) would bath all cages, regardless of infection status. The freshwater bathing frequency in the WS and CS was not related to either bathing strategy ( $p=0.102$ in the WS, $p=0.919$ in the CS). The reported freshwater bathing frequency in the WS was on average 1.69 times $\mathrm{mo}^{-1}$ (SD 1.31) whereas CS freshwater bathing frequency was significantly lower $(p=0.002)$ with 0.65 times $\mathrm{mo}^{-1}$ (SD 0.91) in the CS. The time between freshwater baths ranged on average from $3.6 \mathrm{wk}$ (SD 1.58) in the WS to $15.2 \mathrm{wk}$ (SD 6.03) in the CS. There was a significant association between reported mortality rate in the WS and periods between freshwater baths longer than $7 \mathrm{wk}(\mathrm{p}=0.031)$. Fish were reported to be bathed on average at least $2.3 \mathrm{~h}$ (SD 0.5), ranging from 1.0 to $3.0 \mathrm{~h}$. Different size and size combinations of cages were reported to be used for bathing, including cages with circumferences of 40 and $60 \mathrm{~m}$ (2/25 respondents), of 60 and $80 \mathrm{~m} \mathrm{(5/25}$

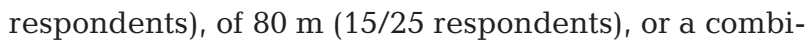
nation of the 3 cage sizes (3/25 respondents). The freshwater bathing frequency in the WS and CS was significantly associated with cage size $(p=0.045$ WS, $\mathrm{p}=0.009$ CS, Table 5).

The reported average stocking density during the freshwater bath was $47.2 \mathrm{~kg} \mathrm{~m}^{-3}$ (SD 4.7) and ranged from 40.0 to $55.0 \mathrm{~kg} \mathrm{~m}^{-3}$, and was associated with the size of the bathing cage $(\mathrm{p}<0.01)$. Stocking densities between 40.0 and $43.0 \mathrm{~kg} \mathrm{~m}^{-3}$ were used in the 40/60 m combination, while stocking densities between 50 and $55 \mathrm{~kg} \mathrm{~m}^{-3}$ were only used in the $80 \mathrm{~m}$ cages. A stocking density of $45.0 \mathrm{~kg} \mathrm{~m}^{-3}$ was used in the $40 / 60 \mathrm{~m}$ combination $(55.6 \%)$ as well as in the 80 $\mathrm{m}$ cages $(44.4 \%)$. Significantly higher bathing frequency were reported both in the WS and CS when the stocking density was reported to be between 42.5 and $43.0 \mathrm{~kg} \mathrm{~m}^{-3}$ (WS: $\mathrm{p}=0.036$; CS: $\mathrm{p}=0.024$ ), and was possibly confounded with the size of the bathing

Table 5. Effect of cage size or cage size combinations used for freshwater bathing on the freshwater bath frequencies per month (SD) in the warm season (WS) and cool season (CS)

\begin{tabular}{|lcc|}
\hline $\begin{array}{l}\text { Cage size circum- } \\
\text { ference(s) }(\mathrm{m})\end{array}$ & \multicolumn{2}{c|}{$\begin{array}{c}\text { Freshwater bathing frequency } \\
\text { WS }\end{array}$} \\
\hline $40,60(\mathrm{n}=2)$ & $3.15(2.62)$ & $2.15(1.91)$ \\
$60,80(\mathrm{n}=5)$ & $2.90(2.07)$ & $1.40(1.08)$ \\
$40,60,80(\mathrm{n}=3)$ & $1.17(0.29)$ & $0.30(0.17)$ \\
$80(\mathrm{n}=15)$ & $1.20(0.25)$ & $0.24(0.23)$ \\
\hline
\end{tabular}


cage. The bath water was always oxygenated during the bathing process. Sixteen $(64 \%)$ respondents reported an oxygenation range between 101 and $140 \%$ while $9(36 \%)$ of the respondents oxygenated between 141 and 180\%. Higher oxygen saturation levels were not associated with the freshwater bathing frequency in the WS $(p=0.831$, Table 6$)$, but were significantly associated with a reported lower mortality rate in this period ( $p=0.004$, Table 6$)$. This association between bathing frequency and mortality rate in the WS was not confounded by the higher freshwater bathing frequency, which is normally employed in this period $(p=0.291)$. In the CS, a higher oxygenation level was significantly associated with a lower reported freshwater bathing frequency $(p=0.001$, Table 6$)$, but not the reported mortality rate $(p=0.283$, Table 7$)$. No relationship could be detected between reported freshwater bathing frequency in the WS and CS, and the reported mortality rate or between these variables and the reported oxygen saturation level of the bathing water. The water during bathing was reported to be either stagnant $(11 / 23$ sites) or actively flowing (12/23 sites). There was no association between the water movement and the reported freshwater bathing frequencies in the WS $(p=0.380)$ and the CS ( $=0.613)$, nor between the reported mortality rate in the WS $(\mathrm{p}=0.344)$. However, a significantly higher reported mortality rate in the CS was found when water in the bath was stagnant $(p=0.033)$.
The fresh water originated from dams (10/25 respondents), rivers $(4 / 25$ respondents), town water, or from a combination of the above (11/25 respondents). Significant associations between the reported freshwater bathing frequencies and reported mortalities, and the source of the bathing water were detected, and results are presented in Table 7 . The reported freshwater bathing frequency was significantly higher when a combination of dam/town water or dam/river water was used in the WS $(p=0.019)$ and the CS $(p=0.008)$. The reported mortality was highest when a combination of dam/town water was used for bathing, both in the WS $(p=0.002)$ and the CS $(p<0.01)$. The reported land use surrounding the freshwater source did not affect the reported freshwater bathing frequency $(p=0.288$ WS, $p=0.294$ CS), nor the reported mortality rate $(p=0.186 \mathrm{WS}, \mathrm{p}=0.612 \mathrm{CS})$.

Bathing origin, defined as the place where cages received their treatment (either at origin or at another lease site), was not significantly associated with the reported freshwater bathing frequency $(\mathrm{p}=$ $0.282 \mathrm{WS}, \mathrm{p}=0.148 \mathrm{CS}$ ) or reported mortality rate $(p=0.219$ WS, $p=0.639$ CS). After the freshwater bath, cages either remained on the site $(18 / 20$ respondents), or were transferred to another site $(2 / 20$ respondents). The cage destination was not associated with the bathing frequency $(\mathrm{p}=0.588 \mathrm{WS}$, $\mathrm{p}=0.195 \mathrm{CS})$ or reported mortality rate $(\mathrm{p}=0.361$ WS, $\mathrm{p}=0.509 \mathrm{CS}$ ).
Table 6. Freshwater bath frequencies per month and percentage of mortalities in the warm season (WS) and cool season (CS) (SD) with the 2 different ranges of reported saturated oxygen used in freshwater bathing

\begin{tabular}{|lcccc|}
\hline & \multirow{2}{*}{ Season } & \multicolumn{2}{c|}{ Saturated oxygen level } \\
& & $101-140 \%$ & $141-180 \%$ \\
\hline Freshwater bath frequency $\mathrm{mo}^{-1}$ & WS & $1.9(1.6) ; \mathrm{n}=16$ & $1.3(0.3) ; \mathrm{n}=9$ \\
Freshwater bath frequency $\mathrm{mo}^{-1}$ & $\mathrm{CS}$ & $0.9(1.0) ; \mathrm{n}=16$ & $0.1(0.2) ; \mathrm{n}=8$ \\
Mortality (\%) & WS & $3.8(1.9) ; \mathrm{n}=15$ & $1.3(0.2) ; \mathrm{n}=9$ \\
Mortality (\%) & CS & $1.3(1.4) ; \mathrm{n}=15$ & $0.4(0.4) ; \mathrm{n}=8$ \\
\hline
\end{tabular}

Table 7. Effects of freshwater origins on freshwater bath frequencies (Fwbf) per month (SD) and mean percentage of mortalities (SD) for the warm season (WS) and cool season (CS)

\begin{tabular}{|lcccc|}
\hline \multirow{2}{*}{ Water source } & \multicolumn{2}{c}{ Fwbf } & \multicolumn{2}{c|}{ Mortality } \\
& WS & CS & WS & CS \\
\hline Dam/tap & $2.70(2.23)$ & $1.24(1.23)$ & $5.80(0.45)$ & $3.00(0.71)$ \\
Dam/river & $3.25(2.48)$ & $2.00(2.12)$ & $0.80(0.99)$ & $0.00(0.00)$ \\
Dam & $1.43(0.29)$ & $0.47(0.30)$ & $2.00(1.16)$ & $0.49(0.57)$ \\
Dam/river/tap & $1.00(0.00)$ & $0.30(0.00)$ & $3.80(0.00)$ & $0.60(0.00)$ \\
River & $1.00(0.00)$ & $0.00(0.00)$ & $1.20(0.00)$ & $0.15(0.30)$ \\
\hline
\end{tabular}

\section{DISCUSSION}

Response rates for questionnaires can be as low as $50 \%$ and questionnaires with a lower response rate should be treated with caution, leading to response bias (Thrusfield 1995). The response rate in our study was high with $91.2 \%$ for Tasmanian and $92.9 \%$ for contacted overseas sites. We have, therefore, assumed that the response bias in our study was minimal. The authors tried to avoid selection of sites on the basis of AGD occurrence. In Tasmania, 2 of the 3 non-respondents were AGD-positive sites, while 1 site was classified as AGD-negative. Overseas, 17 of the contacted respondents were classified as AGDnegative sites. Since most Tasmanian sites were AGD-positive and most contacted overseas sites 
were AGD-negative, some bias could have been introduced into the study results.

The quality of the collected data determines the validity of the questionnaire and is reliant on the accuracy of records, and lack of selection bias, misclassification and confounding (Thrusfield 1995). Certain data types in this study required recall of numerical records, which could originate from existing farm records. These include stocking densities, mortality rate, frequencies of freshwater bathing and net changes, stocking densities during freshwater bathing, duration freshwater bath. Because data recording systems are present on Tasmanian farms, recall bias is unlikely. Nonetheless, these data are clearly subject to measurement errors. Other data on record include the presence or absence of algal blooms or jellyfish and the months of AGD outbreaks (dependent on farmer's opinion of outbreak). Because the accuracy of these data is unknown, they should be treated with caution since they represent the opinion of the individual manager and would be more prone to bias. These questions formed $11.3 \%$ of the total number of questions asked. The AGD status of a site could be reliably determined on Tasmanian sites, while AGD occurrence was confirmed on some of the overseas sites. On Tasmanian sites, regular gill checks (Munday et al. 1993), often followed up by a specific indirect fluorescent antibody test (Howard \& Carson 1993), are used for diagnosis. In Ireland, AGD diagnosis was based on histopathology (H. Rodgers pers. comm.). A previous outbreak in Ireland (Rodger \& McArdle 1996, Palmer et al. 1997) was confirmed using indirect fluorescent antibody testing (IFAT, Howard \& Carson 1993) and PCR (Elliott et al. 2001). On the USA questioned sites, coho salmon were farmed until 1988 and were replaced by Atlantic salmon in 1989. A previous AGD outbreak in this area, involving coho salmon (Kent et al. 1988), was confirmed using IFAT (Howard \& Carson 1993), PCR (Elliott et al. 2001) and histochemistry (DouglasHelders et al. 2001). The AGD outbreaks in the USA dealt with in this study were confirmed by the presence of characteristic pathology of the gills combined with altered fish behaviour.

AGD is a multi-faceted disease, with environmental, host and disease agent factors influencing the occurrence of outbreaks (Douglas-Helders et al. 2002). Possible risk factors were identified by the questionnaire survey through comparison of factors between reported AGD-positive and AGD-negative sites, and results are summarised in Table 2 . They included, among others: (1) mixed sex stocks, and (2) being positioned downstream from 1 or more other salmon farming sites when data was pooled.

The possibility of mixed sex stocks as a risk factor for AGD may be related to maturation. Females are able to release pheromones, which induce the production of sex steroid hormones in males (Olsen et al. 2001). Sex steroids influence the immune status of the fish, often leading to immunosuppression (Bakke \& Harris 1998). For example, there was a 13 -fold increased likelihood of infection with Kudoa thyrsites for sexually mature salmon compared to sexually immature salmon (StHilaire et al. 1998). Also, higher cortisol levels, a measure for primary stress responses (Sadler et al. 2000), were found in mixed sex populations compared to allfemale populations. High cortisol levels have also been associated with immunosuppression (Bakke \& Harris 1998, Sadler et al. 2000).

Paramoebae were found to remain at detectable levels, though at significantly lower numbers, up to $1100 \mathrm{~m}$ away from a farming site, which was the greatest distance measured (Douglas-Helders et al. 2003a). Further, it was demonstrated that Neoparamoeba pemaquidensis did nor require contact with hosts for at least $14 \mathrm{~d}$ to remain infective when a high infection dose was used (Douglas-Helders et al. 2003b). Both studies suggest that the zone of infection around salmon farms could be very extensive (DouglasHelders et al. 2003a). This was seen in this study with farms seemingly at increasing risk of experiencing AGD when located downstream from increasing number of farming sites. This might also have been reflected in this study in the significantly higher freshwater bathing frequency when sites were less than $2 \mathrm{~km}$ apart. These results stress the need for an integrated approach from all farmers within 1 region to manage AGD efficiently.

This questionnaire concerned the year 2000 smolt year-class some $12 \mathrm{yr}$ after the first description of AGD (Munday et al. 1990). Husbandry has been developed over time to minimise losses due to AGD. The higher fallowing frequencies and reported lower stocking densities on AGD-affected sites are probably related to management changes to control AGD. On the overseas sites, where AGD is currently not a great problem, fallowing occurred more frequently on reported AGD-unaffected sites and was negatively associated with the occurrence of AGD. Also, similar stocking densities were reported on AGD affected and unaffected sites. Similarly, no significant difference in reported mortality rate on AGD-affected and ADG-unaffected sites was detected in this study. However, this may merely show that the freshwater bath treatments are successful in controlling AGD. This was also demonstrated by the significant positive association between reported mortality rate and the extension of the period between bathing treatments. Freshwater bathing is, however, very costly (Parsons et al. 2001) and other control or treatment methods should be sought. 
Factors increasing mortality risk which were identified in the questionnaire survey in relation to the freshwater bathing efficacy and number of required treatments were: (1) using a lower oxygen saturation level in the CS, (2) using a combination of dam/tap water or dam/river water for freshwater bathing, and (3) using smaller size bathing cages. Initial freshwater bathing was found to be effective for up to $3 \mathrm{wk}$, with a longer lasting effect at subsequent bathing (Findlay \& Munday 1998, Clark \& Nowak 1999, Nowak 2001). In our study, a significantly higher mortality rate was reported when fish were bathed at longer than $7 \mathrm{wk}$ intervals in the period from November to April. This suggests that regular bathing may be able to control the mortality in the warmer half of the year.

The size of the bathing cage and stocking density within these cages were inter-related and, therefore, its individual effect on bathing efficacy, determined through reported bathing frequency, was difficult to estimate. However, only the stocking densities that were used in the $40 / 60 \mathrm{~m}$ cages showed a significantly increased freshwater bathing frequency. It is, therefore, likely that bathing is less effective in smaller size cages. This could be due to a range of factors such as confinement stress (Sadler et al. 2000), dominant behaviour (MacClean \& Metcalfe 2001) and inability for escapement possibly leading to an increased chance of AGD-affected fish infecting unaffected fish.

Higher reported initial oxygen saturation levels during bathing were negatively associated with the mortality rate in the WS but not the reported bathing frequency. The reported bathing frequencies were negatively associated with the higher reported oxygen level during the CS, but not the number of total mortalities. The association in the WS was not related to the reported increased bathing frequency in that time of the year. During bathing, the oxygen level would decrease through the release of oxygen from the water to the air, which would happen faster with increasing temperatures, as well as to consumption by fish. Previous studies indicated the importance of oxygen, affecting physiological processes during bathing and its effect on Neoparamoeba pemaquidensis survival (Powell et al. 2000, 2001). However, additional trials will be required to confirm findings.

Significant effects on the $\mathrm{pH}$ changes of the freshwater during bathing were found as a result of freshwater origin (Parsons et al. 2001). Also, Neoparamoeba pemaquidensis seemed to show a greater survival in waters rich in $\mathrm{CaCl}_{2}$ and/or $\mathrm{MgCl}_{2}$ (Powell \& Clark 2001). These water quality factors could explain the significant association between both reported mortality rate and bathing frequencies, and freshwater origin, as found in this study. The water source seemed to affect $N$. pemaquidensis removal or kill (as determined by reported bathing frequency) and compromise fish health (as determined by reported mortality rate). Experimentation is needed to determine which water quality factors, and to what extend these factors, affect both $N$. pemaquidensis and fish.

In our study, the only factors which directly affected AGD status according to the questionnaire were the presence of mix sex stocks (TAS), usage of antifouling paints (TAS and OS), automated feeding (OS and Pooled), presence of other salmon farming sites upstream (Pooled), tidal sites (TAS), depth of site (OS and Pooled), rate of salinity change in halocline (TAS, Pooled), and depth of halocline (OS, Pooled). Reduced bathing frequencies, derived from the questionnaire survey, were achieved when bigger size bathing cages were used and a higher oxygen saturation level. Further studies including controlled field trials would be useful to confirm the findings of this study.

Acknowledgements. The authors thank the Tasmanian salmonid industry and overseas salmon growers for their participation with the questionnaire, A. Cameron for his useful comments, M. Powell for his useful comments on freshwater bathing and physiology and provision of the Tasmanian map with salmon farms, and the Co-operative Research Centre for Aquaculture for the award of a PhD scholarship to G.M.D.-H.

\section{LITERATURE CITED}

Bakke TA, Harris PD (1998) Diseases and parasites in wild Atlantic salmon (Salmo salar) populations. Can J Fish Aquat Sci 55:247-266

Clark A, Nowak BF (1999) Field investigations of amoebic gill disease in Atlantic salmon, Salmo salar L., in Tasmania. J Fish Dis 22:433-443

Davidson J (1999) Determinants of disease. In: Aquaculture epidemiology. Canadian Aquaculture Institute, International education in aquaculture medicine and management, Sydney, p 1-6

Dean AG, Dean JA, Coulombier D, Brendel KA and 6 others (1995) Epi Info, Version 6. A word-processing, database, and statistical program for public health on IBM-compatible microcomputers. Centers for Disease Control and Prevention, Atlanta, GA

Douglas-Helders GM (2002) Epidemiology of amoebic gill disease. PhD thesis, University of Tasmania, Launceston

Douglas-Helders GM, Saksida S, Raverty S, Nowak BF (2001) Temperature as a risk factor for outbreaks of amoebic gill disease in farmed Atlantic salmon (Salmo salar). Bull Eur Assoc Fish Pathol 21:114-116

Douglas-Helders GM, Handlinger J, Carson J, Nowak BF (2003a) Assessment over time of the infectivity of gill derived and seawater dispersed Neoparamoeba pemaquidensis (Page 1987). Bull Eur Assoc Fish Pathol 23: 35-39

Douglas-Helders GM, O'Brien DP, McCorkell BE, Zilberg D, Gross A, Carson J, Nowak BF (2003b) Temporal and spatial distribution of Paramoeba sp. in the water column —a pilot study. J Fish Dis 26:1-10

Dyková I, Novoa B (2001) Comments on diagnosis of amoebic gill disease (AGD) in turbot, Scophthalmus maximus. Bull Eur Assoc Fish Pathol 21:40-44 
Dyková I, Figueras A, Peric Z (2000) Neoparamoeba Page, 1987: light and electron microscopic observations on six strains of different origin. Dis Aquat Org 43:217-223

Elliott N, Wong F, Carson J (2001) Detection and abundance of Paramoeba species in the environment. FRDC project 1998/209. Fisheries Research \& Development Corporation, Hobart

Findlay VL, Munday BL (1998) Further studies on acquired resistance to AGD in Atlantic salmon. J Fish Dis 21:121-125

Frankena K, Thrusfield MV (1997) Basics of observational studies. In: Noordhuizen JPTM, Franekna K, van der Hoofd CM, Graat EAM (eds) Application of quantitative methods in veterinary epidemiology. Wageningen Press, Wageningen, p 99-134

Howard T, Carson J (1993) Verification that Paramoeba species are consistently associated with gill damage in fish affected with amoebic gill disease. In: Valentine P (ed) Proceedings of the Saltas research and development review seminar, Tasmania 1993. Salmon Enterprises of Tasmania Pty Ltd Dover, Tasmania, p 69-80

Kent ML, Sawyer TK, Hendrick RP (1988) Paramoeba pemaquidensis (Saromastigophora: Paramoebidae) infestation of the gills of coho salmon Oncorhynchus kisutch, reared in seawater. Dis Aquat Org 5:163-169.

MacClean A, Metcalfe NB (2001) Social status, access to food, and compensatory growth in juvenile Atlantic salmon. J Fish Biol 58:1331-1346

Martin SW, Meek AH, Willeberg P (1987) Veterinary epidemiology: principles and methods. Iowa State University Press, Ames, IA

Menzies FD, Crockford T, McLoughlan MF, Wheatley SB, Goodall EA (1998) An epidemiological approach to investigating disease and production losses in farmed Atlantic salmon. In: Barnes A, Davidson G, Hiney M, McIntosh D (eds) Methodology in fish diseases research. Fisheries Research Services, Aberdeen, p 289-294

Munday BL, Foster CK, Roubal FR, Lester RJG (1990) Paramoebic gill infection and associated pathology of Atlantic salmon, Salmo salar, and rainbow trout, Salmo gairdeneri, in Tasmania. In: Perkins FO, Cheng TC (eds) Pathology in marine science. Academic Press, San Diego, p 215-222

Munday BL, Lange K, Foster C, Lester RJG, Handlinger J (1993) Amoebic gill disease of sea-caged salmonids in

Editorial responsibility: Chris Baldock,

Brisbane, Queensland, Australia
Tasmanian waters. Tasm Mar Fish Res 28:14-19

Munday BL, Zilberg D, Findlay V (2001) Gill disease of marine fish caused by infection with Neoparamoeba pemaquidensis. J Fish Dis 24:497-507

Nowak BF (2001) Qualitative evaluation of risk factors for amoebic gill disease in Atlantic salmon. In: Rogers CJ (ed) Proceedings of the OIE international conference on risk analysis in aquatic animal health, 8-10 February 2000. Office International des Epizooties (OIE), Paris, p 148-155

Olsen KH, Bjerselius R, Mayer I, Kindahl H (2001) Both ovarian fluid and female urine increase sex steroid hormone levels in mature Atlantic salmon (Salmo salar) male parr. J Chem Ecol 27:2337-2350

Palmer R, Carson J, Ruttledge M, Drinan E, Wagner T (1997) Gill disease associated with Paramoeba, in sea-reared Atlantic salmon in Ireland. Bull Eur Assoc Fish Pathol 3:112-114

Parsons H, Nowak B, Fisk D, Powell M (2001) Effectiveness of commercial freshwater bathing as a treatment against amoebic gill disease in Atlantic salmon. Aquaculture 195: 205-210

Powell MD, Clark GA (2001) Bath additives for removal of Paramoeba from salmon gills: efficacy and toxicity. In: Battaglene SC, Cobcroft JM (eds) The first scientific conference of the Atlantic salmon sub-program handbook. CSIRO Marine Laboratories, Hobart, p 17-18

Powell MD, Fisk D, Nowak BF (2000) Effects of graded hypoxia on Atlantic salmon infected with amoebic gill disease. J Fish Biol 57:1047-1057

Powell MD, Parsons HJ, Nowak BF (2001) Physiological effects of freshwater bathing of Atlantic salmon (Salmo salar) as treatment for amoebic gill disease. Aquaculture 199:259-266

Rodger HD, McArdle JF (1996) An outbreak of amoebic gill disease in Ireland. Vet Rec 139:348-349

Sadler J, Pankhurst NW, Pankhurst PM, King H (2000) Physiological stress responses to confinement in diploid and triploid Atlantic salmon. J Fish Biol 56:506-518

St-Hilaire S, Ribble C, Whitaker DJ, Kent M (1998) Prevalence of Kudoa thyrsites in sexually mature and immature pen-reared Atlantic salmon (Salmo salar) in British Columbia, Canada. Aquaculture 162:69-77

Thrusfield M (1995) Veterinary epidemiology. Blackwell Science, Oxford

Submitted: December 17, 2002; Accepted: June 2, 2004

Proofs received from author(s): January 19, 2004 